\title{
Indian hedgehog gene transfer is a chondrogenic inducer of human mesenchymal stem cells
}

\author{
Andre F Steinert ${ }^{1 *}$, Manuel Weissenberger ${ }^{1}$, Manuela Kunz ${ }^{1}$, Fabian Gilbert ${ }^{1}$, Steven C Ghivizzani ${ }^{2}$, Sascha Göbel ${ }^{1}$, \\ Franz Jakob ${ }^{1}$, Ulrich Nöth ${ }^{1}$ and Maximilian Rudert ${ }^{1}$
}

\begin{abstract}
Introduction: To date, no single most-appropriate factor or delivery method has been identified for the purpose of mesenchymal stem cell (MSC)-based treatment of cartilage injury. Therefore, in this study we tested whether gene delivery of the growth factor Indian hedgehog $(\mathrm{IHH})$ was able to induce chondrogenesis in human primary MSCs, and whether it was possible by such an approach to modulate the appearance of chondrogenic hypertrophy in pellet cultures in vitro.
\end{abstract}

Methods: First-generation adenoviral vectors encoding the CDNA of the human $\mathrm{IHH}$ gene were created by cre-lox recombination and used alone or in combination with adenoviral vectors, bone morphogenetic protein-2 (Ad.BMP2 ), or transforming growth factor beta-1 (Ad.TGF- $\beta$ 1) to transduce human bone-marrow derived MSCs at $5 \times 10^{2}$ infectious particles/cell. Thereafter, $3 \times 10^{5}$ cells were seeded into aggregates and cultured for 3 weeks in serumfree medium, with untransduced or marker gene transduced cultures as controls. Transgene expressions were determined by ELISA, and aggregates were analysed histologically, immunohistochemically, biochemically and by RT-PCR for chondrogenesis and hypertrophy.

Results: $I H H, T G F-\beta 1$ and BMP-2 genes were equipotent inducers of chondrogenesis in primary MSCs, as evidenced by strong staining for proteoglycans, collagen type II, increased levels of glycosaminoglycan synthesis, and expression of mRNAs associated with chondrogenesis. $\mathrm{HH}$-modified aggregates, alone or in combination, also showed a tendency to progress towards hypertrophy, as judged by the expression of alkaline phosphatase and stainings for collagen type $X$ and Annexin 5 .

Conclusion: As this study provides evidence for chondrogenic induction of MSC aggregates in vitro via IHH gene delivery, this technology may be efficiently employed for generating cartilaginous repair tissues in vivo.

\section{Introduction}

None of the current approaches to cartilage regeneration, including cell-based therapies, have generated long-lasting hyaline neo-cartilage repair tissue in vivo [1]. By means of microfracture treatment, which allows mesenchymal stem cells (MSCs) from the subchondral bone to enter the cartilage defect, MSC-based treatments of cartilage lesions have become part of our daily clinical routine. But administration of ex vivo amplified MSCs to repair full-thickness articular cartilage defects in humans has also been introduced into the clinical

\footnotetext{
* Correspondence: a-steinert.klh@uni-wuerzburg.de

'Department of Orthopaedic Surgery, König-Ludwig-Haus, Center for Musculoskeletal Research, Julius-Maximilians-University, Brettreichstraße 11, Würzburg 97074, Germany

Full list of author information is available at the end of the article
}

arena as an alternative to transplantation of autologous chondrocytes $[2,3]$. However, for such MSC-based therapeutic interventions to be successful, the creation of an appropriate three-dimensional environment that allows induction of chondrogenesis and maintenance of the chondrogenic phenotype in vivo is of key importance $[1,4]$. To achieve this goal probably requires administration of appropriate growth factors at adequate doses, which facilitate the desired aspects of repair. Among these growth factors, the members of the transforming growth factor beta (TGF- $\beta$ ) superfamily have been most extensively analysed, along with many others $[5,6]$. Furthermore, to overcome the limitations of inadequate delivery of the soluble factors for chondrogenic induction and maintenance, genetic interventions have been

\section{Biomed Central}

(c) 2012 Steinert et al.; licensee BioMed Central Ltd. This is an open access article distributed under the terms of the Creative Commons Attribution License (http://creativecommons.org/licenses/by/2.0), which permits unrestricted use, distribution, and reproduction in any medium, provided the original work is properly cited. 
explored clinically [7] and extensively in experimental models in vitro and in vivo [8-10].

Remarkably, despite the fast-growing body of literature on this topic, no single most-appropriate factor and delivery method has been identified for the purpose of hyaline cartilage regeneration that justified approval for testing in humans. One hurdle that might impair stable neo-cartilage formation is the issue of chondrogenic hypertrophy, which has been identified in studies on MSC-mediated chondrogenesis using several bone morphogenetic proteins (BMPs) in vitro and in vivo $[1,8,11-13]$. When analysing such models, it appears that BMP-2 and others not only drive MSCs toward chondrogenesis, but also mediate endstage chondrocyte maturation, hypertrophy and apoptosis, which concurs with endochondral ossification during limb development but is unwanted in cartilage defects [1]. In this context, modulators of chondrogenic hypertrophy in the growth plate such as parathyroid hormone-related peptide (PTHrP) and Indian hedgehog (IHH) [14] appear to be of great interest for the development of MSC-based cartilage repair approaches. Therefore, having extensively explored chondrogenesis in primary MSCs along with the issue of hypertrophy following adenoviral-mediated gene delivery of TGF- $\beta 1$ and BMP- 2 in previous work using pellet cultures in vitro $[8,11,15]$, the purpose of this study was to explore the effects of IHH gene transfer in this model.

\section{Materials and methods Generation and propagation of recombinant adenoviral vectors}

The full-length cDNA clone of the human IHH gene [GenBank:BC034757, GenBank:BI517875] was released from the carrier pCMV-SPORT6 plasmid (MGC-34815; American Type Culture Collection, Manassas, VA, USA) and the 1.4 kB insert was cloned into Xba/Xho sites of the pAdlox adenoviral shuttle vector [16] according to standard protocols [17]. First-generation, E1-deleted and E3-deleted, serotype 5 adenoviral vectors carrying the cDNAs for human IHH were constructed by cre-lox recombination as described earlier [16] and were designated Ad.IHH. The vectors encoding GFP from jellyfish, TGF- $\beta 1$ and BMP-2 were generated, amplified, purified and used as described earlier $[11,16,18]$. Virus stock titres were determined by optical density at $260 \mathrm{~nm}$ and standard plaque assay, and ranged between $10^{12}$ and $10^{13}$ particles $/ \mathrm{ml}$.

Transduction and culture of human marrow-derived MSCs Human bone marrow-derived MSCs were isolated from marrow reamings of femurs from five patients, aged 48 to 62 years (mean age 54 years), undergoing total hip replacement surgery after informed consent and as approved by the institutional review board of the
University of Würzburg as described earlier [11,19]. Briefly, the collected cells were spun, resuspended and placed in tissue culture using complete DMEM containing $10 \%$ foetal bovine serum and $1 \%$ penicillin/streptomycin, $1 \mathrm{ng} / \mathrm{ml}$ fibroblast growth factor-2 (all Invitrogen $\mathrm{GmbH}$, Darmstadt, Germany). At confluency, cells were trypsinised, counted, replated and transduced at $5 \times 10^{2}$ infectious particles/cell for each vector for 2 hours. Marker gene controls were also maintained along with cultures that remained uninfected and received, or not, supplementation with recombinant $10 \mathrm{ng} / \mathrm{ml}$ TGF- $\beta 1$ protein (R\&D Systems, Minneapolis, MN, USA).

\section{Pellet culture and assessment of transgene expression}

Following infection, MSCs were placed in pellet cultures as previously described [11]. Briefly, MSCs were suspended in serum-free DMEM containing $1 \mathrm{mM}$ pyruvate, 1\% ITS+ Premix, $37.5 \mathrm{mg} / \mathrm{ml}$ ascorbate-2-phosphate and $10^{-7} \mathrm{M}$ dexamethasone (all Sigma, St Louis, MO, USA), and then $300 \mu \mathrm{l}$ aliquots $\left(3 \times 10^{5}\right.$ cells $)$ were distributed to a polypropylene, V-bottomed 96-well plate (Corning, Corning, NY, USA) to promote aggregate formation. As already mentioned, control aggregates were maintained that remained uninfected and received, or not, $10 \mathrm{ng} / \mathrm{ml}$ TGF- $\beta 1$ recombinant protein (all R\&D Systems). Pellets formed within 24 hours and cultures were maintained at $37^{\circ} \mathrm{C}, 5 \% \mathrm{CO}_{2}$ with changes of fresh media being performed every 2 to 3 days until harvest at various time points for further analyses. Twenty-four-hour-conditioned media were collected at several time points and assayed for TGF- $\beta 1$, BMP-2 (R\&D Systems) and IHH (Cusabio Biotech Co. Ltd, Newark, DE, USA) expression using commercially available ELISA kits.

\section{Osteogenic and adipogenic differentiation}

For confirmation of the multilineage differentiation plasticity, selected MSC preparations were additionally tested for their capacity to differentiate along osteogenic or adipogenic lineages as described earlier [20]. MSC monolayer cultures were therefore seeded at a density of $1 \times 10^{5}$ cells $/ \mathrm{cm}^{2}$ in four-well chamber slides (Nunc, Wiesbaden, Germany). For osteogenic induction, media were supplemented with $10^{-7} \mathrm{M}$ dexamethasone, $50 \mu \mathrm{g} / \mathrm{ml}$ ascorbate, $10 \mathrm{mM} \beta$-glycerophosphate, and $25 \mathrm{ng} / \mathrm{ml}$ recombinant human BMP-2 (R\&D Systems). Adipogenesis was induced on separate monolayer cultures by supplementing the media with $1 \mu \mathrm{M}$ dexamethasone, $1 \mu \mathrm{g} / \mathrm{ml}$ insulin, $0.5 \mathrm{mM} 3$-isobutyl-1-methylxanthine and $100 \mu \mathrm{M}$ indomethacin (all Sigma). Control cultures without osteogenic or adipogenic supplements were also maintained. After 3 weeks, cultures were fixed and osteogenic cultures were stained histochemically for alkaline phosphatase (ALP; Sigma) or for matrix mineralisation using Alizarin Red (Sigma), while adipogenic cultures were stained with Oil 
Red $\mathrm{O}$ for the detection of lipid droplets as previously reported [20].

\section{Biochemical assays}

Biochemical analyses for assessment of cell proliferation, glycosaminoglycan (GAG) synthesis and ALP activity were performed as described previously and as directed by the respective supplier [11]. Briefly, to evaluate cell proliferation a quantitative detection of ATP was performed using the CellTiter-Glo ${ }^{\circledR}$ Luminescent Cell Viability Assay (Promega, Madison, WI, USA). GAG contents were measured following papain digestion $(1 \mu \mathrm{g} / \mathrm{ml}$; Sigma) by reaction with 1,9-dimethylmethylene blue using the Blyscan ${ }^{\mathrm{TM}}$ Sulfated Glycosaminoglycan Assay (Biocolor Ltd, Newtownabbey, Northern Ireland). ALP activity in aggregates was analysed using a kit (Sigma) via absorbance at $405 \mathrm{~nm}$ by the conversion of $p$-nitrophenyl phosphate to $p$-nitrophenol and inorganic phosphate in an ELISA reader, using a standard curve. Values of the GAG and ALP assays were normalised to DNA content, as determined by the QuantiT ${ }^{\mathrm{TM}}$ PicoGreen ${ }^{\circledR}$ kit (Invitrogen).

\section{Histology and immunohistochemistry}

Histological analyses were performed on aggregates fixed in $4 \%$ paraformaldehyde, following dehydration, paraffin embedding, sectioning and staining with $\mathrm{H} \& \mathrm{E}$ and Alcian Blue (all Sigma) as outlined previously [11]. ALP staining was performed using a histochemical ALP staining kit according to the manufacturer's instructions (Sigma). Alternate sections were subjected to immunohistochemistry using pre-digestions and antibody treatments as follows: collagen (COL) type II - pepsin ( $1 \mathrm{mg} / \mathrm{ml}$; Sigma)/ monoclonal anti-COL type II antibodies (Acris Antibodies $\mathrm{GmbH}$, Hiddenhausen, Germany); chondroitin-4-sulphate (CS4) - chondroitinase ABC (5 U/ml; Sigma)/polyclonal anti-CS4 antibodies (Millipore GmbH, Schwalbach, Germany); and COL type $\times-0.25 \%$ trypsin (Sigma)/polyclonal anti-COL type $\mathrm{X}$ antibodies (Calbiochem, Bad Soden, Germany). Immunostainings were visualised by treatment with Advance ${ }^{\mathrm{TM}}$ HRP link and Advance ${ }^{\mathrm{TM}}$ HRP enzyme (Dako, Hamburg, Germany), followed by diaminobenzidine staining (DAB Kit; Sigma). The slides were finally counterstained with hemalaun (Merck, Darmstadt, Germany). For all immunohistochemical analyses, controls were performed with non-immune IgG (Sigma) instead of the primary antibodies.

\section{Annexin 5 assay}

Annexin 5 expression was assessed as a marker of hypertrophy and apoptosis as described previously [11], and as directed by the supplier (Sigma). Briefly, the test uses double-labelling with the red fluorochome Cy3.18/Annexin 5$\mathrm{Cy} 3$ that binds to early apoptotic cells and conversion of 6-carboxyfluorescein diacetate (nonfluorescent) to 6-carboxyfluorescein (green fluorescent) by living cells. Following incubation with double-labelling staining solution for 10 minutes, aggregates were washed, fixed in $4 \%$ paraformaldehyde, and processed to paraffin sections at $4 \mu \mathrm{m}$. Evaluation of living and apoptotic cells was performed on representative sections using a fluorescence microscope and the appropriate green and red filters.

\section{RNA extraction and RT-PCR analyses}

On days 3, 7, 14 and 21 RNA was extracted from six to $10 \mathrm{MSC}$ aggregates per group and donors using $1 \mathrm{ml}$ Trizol reagent (Invitrogen) and an additional purification step with separation columns including a DNase treatment according to the manufacturer's instructions (NucleoSpin RNA II Kit; Macherey-Nagel GmbH, Düren, Germany). RNA from pellets of each condition (2 $\mu \mathrm{g}$ each group) was used for reverse transcription using random hexamer primers and BioScript reverse transcriptase (Bioline $\mathrm{GmbH}$, Luckenwalde, Germany). Equal amounts (100 ng) of each cDNA were used as templates for PCR amplification in a $30 \mu$ reaction volume using MangoTaq DNA Polymerase Taq (Bioline $\mathrm{GmbH}$ ) and 5 pmol of gene-specific primers as listed in Table 1 , with elongation factor- $1 \alpha$ (EF-1 $\alpha)$ serving as the housekeeping gene and internal control. The RTPCR products were run on $1.5 \%$ agarose gels containing $0.1 \mathrm{mg} / \mathrm{ml}$ ethidium bromide, and were visualised using the Bio Profile software (LTF, Wasserburg, Germany).

For semi-quantitative PCR analyses, equal amounts (100 ng) of each cDNA were used as templates for amplification in a $30 \mu \mathrm{l}$ reaction volume using MangoTaq DNA Polymerase Taq (Bioline $\mathrm{GmbH}$ ) and 5 pmol of gene-specific primers, which were used to detect mRNA transcripts characteristic of chondrogenic, hypertrophic or osteogenic differentiation states. The sequences, annealing temperatures and product sizes of forward and reverse primers used for COL type II, aggrecan core protein (AGN), cartilage oligomeric matrix protein (COMP), fibromodulin, sex determining region Y-box 9 (SOX9), COL type I, COL type X, osteopontin (OP), and osteocalcin are listed in Table 1, with EF- $1 \alpha$ serving as the housekeeping gene and internal control. The RT-PCR products were electrophoretically separated on $1.5 \%$ agarose gels containing $0.1 \mathrm{mg} / \mathrm{ml}$ ethidium bromide and visualised using Bio Profile software (LTF), allowing correlation between EF-1 $\alpha$ signals and cycle number for each sample. The densities of the PCR bands were analysed with the Bio 1D/Capt MW software (LTF), and the mean ratio (fold change) and standard deviation, normalised to expression of the EF$1 \alpha$ housekeeping gene, were calculated from three bands (one per patient). 
Table 1 Primer details used for RT-PCR analyses

\begin{tabular}{|c|c|c|c|c|}
\hline Gene & RT-PCR primer sequences $\left(5^{\prime}\right.$ to $\left.3^{\prime}\right)$ & Annealing temperature $\left({ }^{\circ} \mathrm{C}\right)$ & Product size (base pairs) & Cycles \\
\hline \multicolumn{5}{|c|}{ Chondrogenic markers } \\
\hline \multirow[t]{2}{*}{ COL type II } & Sense: TTCCCAGGTCAAGATGGTC & 58.0 & 374 & 35 \\
\hline & Antisense: CTTCAGCACCTGTC CACCA & & & \\
\hline \multirow[t]{2}{*}{$A G N$} & Sense: TGAGGAGGGCTGGAACAAGTACC & 54.0 & 392 & 30 \\
\hline & Antisense: GGAGGTGGTAATTGCAGGGAACA & & & \\
\hline \multirow[t]{2}{*}{ COMP } & Sense: CAGGACGACTTTGATGCAGA & 54.0 & 312 & 32 \\
\hline & Antisense: AAGCTGGAGCTGTCTGGTA & & & \\
\hline \multirow[t]{2}{*}{ FMD } & Sense: CTTACCCCTATGGGGTGGAT & 54.0 & 389 & 35 \\
\hline & Antisense: GTACATGGCCGTGAGGAAGT & & & \\
\hline \multirow[t]{2}{*}{ SOX9 } & Sense: ATCTGAAGAAGGAGAGCGAG & 58.0 & 263 & 35 \\
\hline & Antisense: TCAGAAGTCTCCAGAGCTTG & & & \\
\hline \multicolumn{5}{|c|}{ Hypertrophy and osteogenic markers } \\
\hline \multirow[t]{2}{*}{ COL type $X$} & Sense: CCCTIITGGTGCTAGTATCC & 54.0 & 468 & 25 \\
\hline & Antisense: CTGTTGTCCAGGTTTTCCTGGCAC & & & \\
\hline \multirow[t]{2}{*}{$\mathrm{OP}$} & Sense: ACGCCGACCAAGGAAAACTC & 51.0 & 483 & 35 \\
\hline & Antisense: GTCCATAAACCACACTATCACCTCG & & & \\
\hline \multirow[t]{2}{*}{ COL type I } & Sense: GGACACAATGGATTGCAAGG & 54.0 & 461 & 32 \\
\hline & Antisense: TAACCACTGCTCCACTCTGG & & & \\
\hline \multirow[t]{2}{*}{ OC } & Sense: ATGAGAGCCCTCACACTCCTC & 59.0 & 387 & 35 \\
\hline & Antisense: GCCGTAGAAGCGCCGATAGGC & & & \\
\hline \multirow[t]{2}{*}{ ALP } & Sense: TGGAGCTTCAGAAGCTCAACACCA & 51.0 & 454 & 35 \\
\hline & Antisense: TCTCGTTGTCTGAGTACCAGTCC & & & \\
\hline \multicolumn{5}{|l|}{ Internal control } \\
\hline \multirow[t]{2}{*}{$E F-1 \alpha$} & Sense: AGGTGATTATCCTGAACCATCC & 54.0 & 234 & 25 \\
\hline & Antisense: AAAGGTGGATAGTCTGAGAAGC & & & \\
\hline
\end{tabular}

AGN, aggrecan core protein; ALP, alkaline phosphatase; COL, collagen; COMP, cartilage oligomeric matrix protein; EF-1 $\alpha$, elongation factor $1 \alpha$; FMD, fibromodulin; OC, osteocalcin; OP, osteopontin; SOX9, sex determining region Y-box 9.

\section{Statistical analysis}

Data from the ELISA, ATP, GAG, DNA, ALP and PCR analyses were expressed as mean values \pm standard deviation, with each experiment being performed in triplicate or quadruplicate ( $n=3$ to 4 ), and were repeated on at least three to five individual marrow preparations from different patients ( $n=3$ to 5 ), as indicated in the respective experiments. Numerical data for ATP, GAG, DNA, and ALP were subjected to variance analysis (one-factor or two-factor analysis of variance), and statistical significance was determined by Student's $t$ test with $P<0.05$ considered significant.

\section{Results}

\section{Multilineage differentiation}

Pellet cultures of MSCs derived from bone marrow underwent chondrogenic differentiation in the presence, but not in the absence, of TGF- $\beta 1$ as judged by strong metachromatic staining of proteoglycans with Alcian blue (Figure 1, left panels). Monolayer cultures of MSCs responded equivalently to osteogenic or adipogenic medium in terms of strong staining for ALP, mineralisation with Alizarin Red (Figure 1, middle panels), or staining with Oil Red O for lipid droplets (Figure 1, right panels), while only weak staining was observed in the respective control cultures.

\section{Transgene expression of genetically modified pellet cultures}

Pellet cultures modified with adenoviral vectors encoding $\mathrm{IHH}$ alone or together with TGF- $\beta 1$ or BMP- 2 generated high levels of transgene product at day 3 of culture, with dose ranges of 150 to $250 \mathrm{pg} / \mathrm{ml}$ for IHH (Figure 2a), 15 to $20 \mathrm{ng} \mathrm{ng} / \mathrm{ml}$ for TGF- $\beta 1$ (Figure $2 \mathrm{~b}$ ) and 120 to $160 \mathrm{ng} / \mathrm{ml}$ for BMP-2 (Figure 2c), and declining values over time as evidenced by ELISA. This corresponds to previous findings using adenoviral vectors alone $[8,11,15]$ or in combination [11]. The respective values in the marker gene controls (Figure 2a to $2 \mathrm{c}$ ) were persistently very low $(<10 \mathrm{pg} / \mathrm{ml})$, and were equivalent to the levels observed in the naïve controls (data not shown).

\section{Histological and immunohistochemical analyses of chondrogenesis}

Transduction of MSCs with Ad.IHH (IHH; Figure 3b), Ad.IHH and Ad.TGF- $\beta 1$ (IHH + TGF- $\beta 1$; Figure $3 \mathrm{c}$ ), or Ad.IHH and Ad.BMP-2 (IHH + BMP-2; Figure 3d) induced a significant chondrogenic response in the 


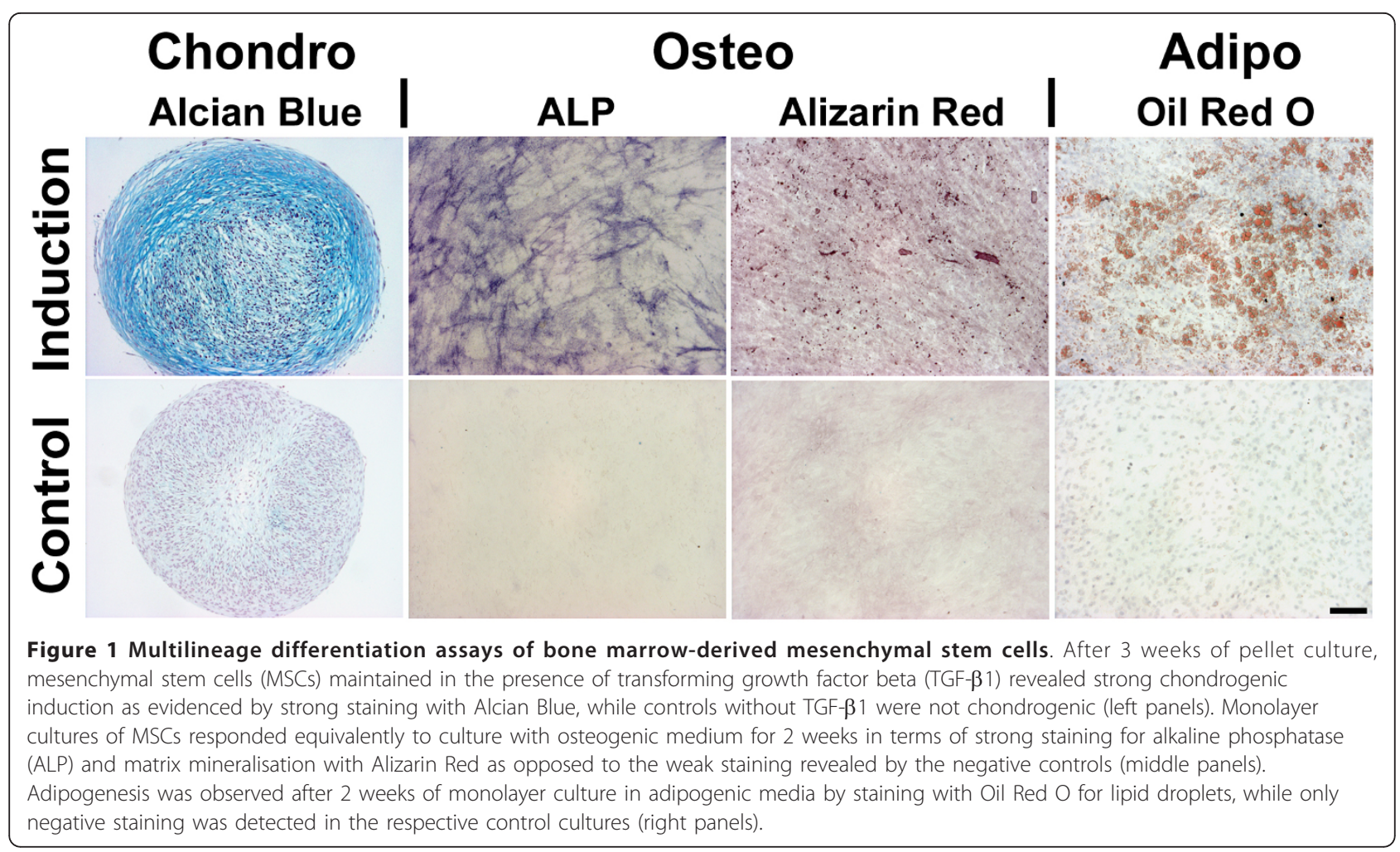

respective pellet cultures over time compared with the Ad.GFP cultures (positive control; Figure 3a), which were not chondrogenic. Cellularity of the respective groups after 10 and 21 days is shown by $\mathrm{H} \& \mathrm{E}$ staining of representative aggregate sections in Figure 3a, b (left panels). Chondrogenic differentiation was evidenced by strong metachromatic staining for proteoglycans with Alcian Blue (Figure 3a to $3 \mathrm{~d}$, right panels) in the extracellular matrix of the IHH, IHH + TGF- $\beta 1$, and $\mathrm{IHH}+\mathrm{BMP}-2$ pellets compared with the marker gene negative controls. Only the comparative positive control groups TGF- $\beta 1$ or BMP- 2 also revealed a chondrogenic phenotype for both stains (Figure 3e).

Correspondingly, immunohistochemistry for cartilage matrix proteins COL type II (Figure 4 a to $4 \mathrm{~d}$, left panels) and CS4 (Figure 4a to 4d, right panels) showed

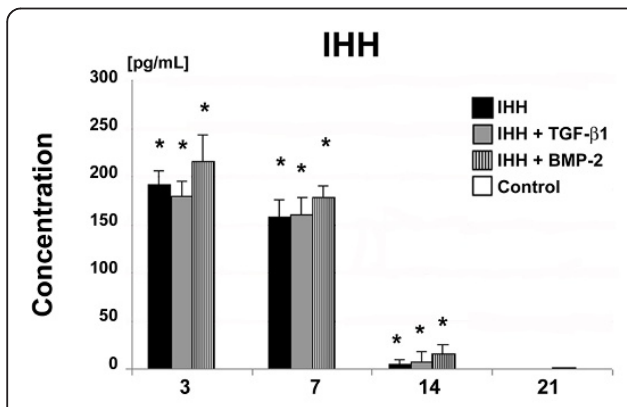

(a)

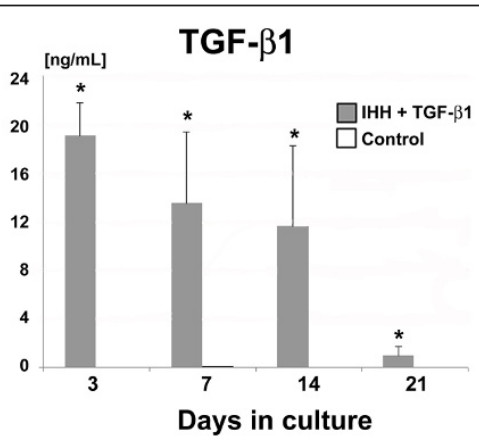

(b)

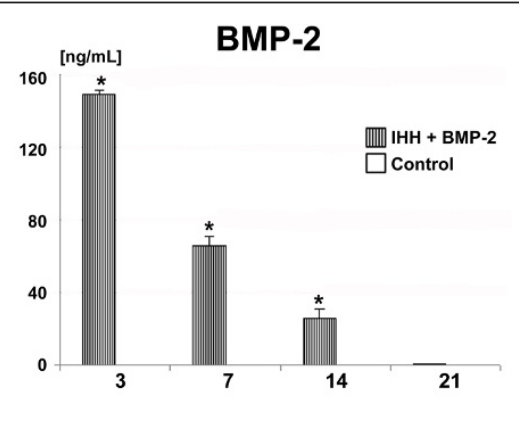

(c)

Figure 2 Transgene expression of mesenchymal stem cell aggregates following adenoviral Indian hedgehog gene transfer. Primary mesenchymal stem cells were modified with Ad.GFP (controls), Ad.IHH alone (IHH), or in combination with Ad.TGF- $\beta 1$ (IHH + TGF- $\beta 1$ ) or Ad. BMP-2 (IHH + BMP-2), seeded into pellets and analysed during a 21-day time course. Values represent levels of (a) IHH, (b) TGF- $\beta$ 1, or (c) BMP-2 transgene product in the conditioned media by the respective groups over 24 hours at the time points indicated. Mean \pm standard deviation from three aggregates per condition and marrow preparation from three marrow preparations from different patients is shown. *Significant differences $(P<0.05)$ compared with controls. Ad., adenoviral vector; BMP, bone morphogenetic protein; IHH, Indian hedgehog; TGF- $\beta$, transforming growth factor beta. 

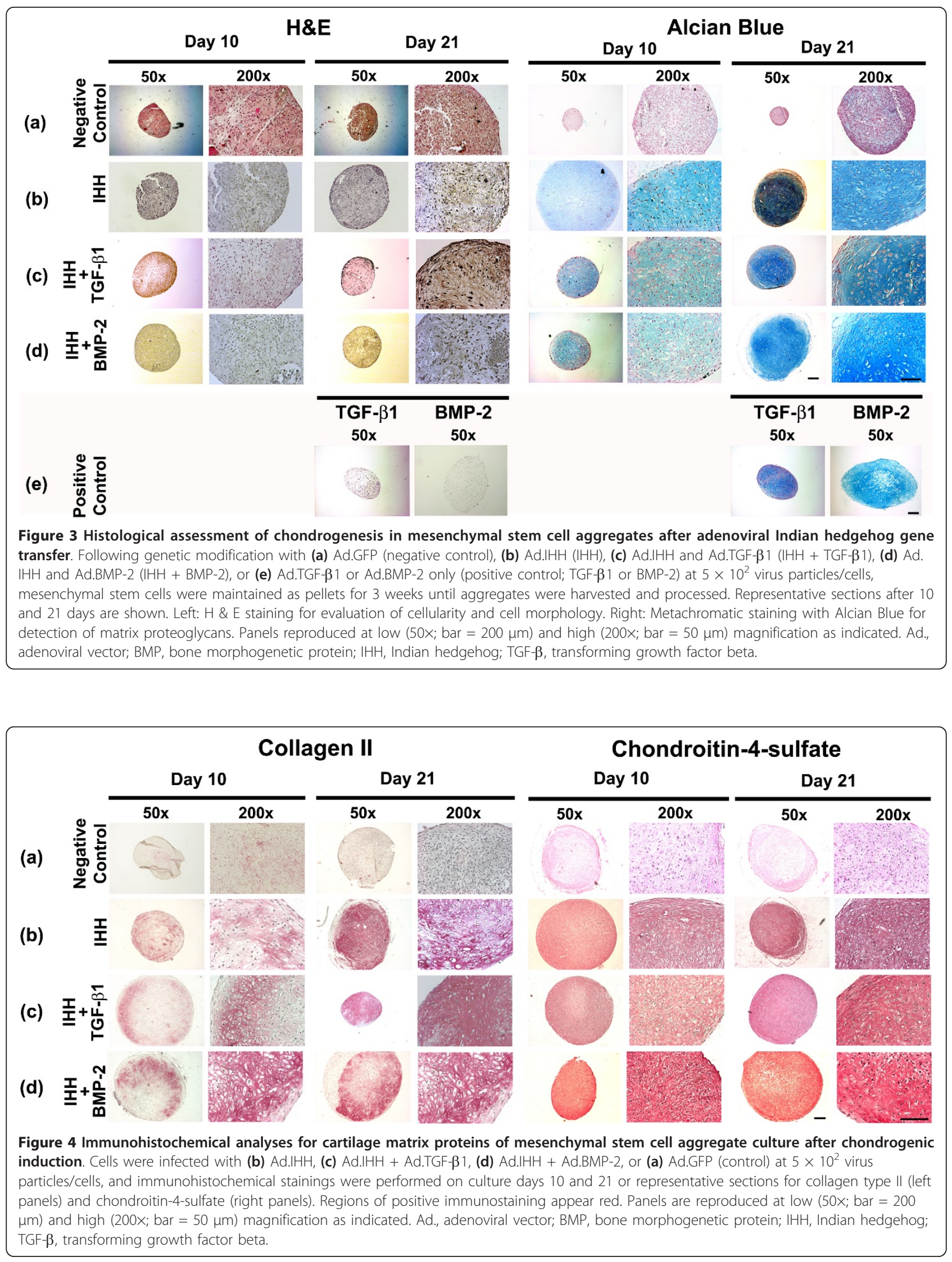
a strong production of these cartilage matrix proteins at days 10 and 21 of culture in the IHH (Figure 4b), $\mathrm{IHH}+\mathrm{TGF}-\beta 1$ (Figure 4c), and IHH + BMP-2 aggregates (Figure 4d) relative to the Ad.GFP controls (Figure 4a), which showed only very low levels of staining for both markers. Clear-cut differences in the chondrogenic appearance of the immunophenotype between the $\mathrm{IHH}$, $\mathrm{IHH}+\mathrm{TGF}-\beta 1$, and $\mathrm{IHH}+\mathrm{BMP}-2$ aggregates were not observed (Figure $4 \mathrm{~b}$ to $4 \mathrm{~d}$ ).

Aggregates transduced with TGF- $\beta 1$ or BMP- 2 only, as well as untransduced pellets maintained in the presence of $10 \mathrm{ng} / \mathrm{ml}$ recombinant TGF- $\beta 1$ protein, were all also chondrogenic, while control cultures without gene or growth factor supplementation were nonchondrogenic, by means of positive staining for Alcian Blue (Figure 1, left panels) and immunohistochemistry (data not shown) for COL type II and CS4. This finding corresponds with findings published extensively in previous work $[8,11,15]$.

\section{Hypertrophic differentiation and apoptosis}

Immunohistochemistry for COL type $\times$ (Figure $5 \mathrm{a}$ to $5 \mathrm{~d}$, left panels) and staining for ALP (Figure 5a to 5d, right panels) were performed on representative aggregate sections after days 10 and 21 of culture and were used as markers for chondrocyte hypertrophy. Negative controls (Ad.GFP) showed no detectable staining for COL type $x$ (Figure 5a, left panels) and ALP (Figure 5a, right panels). In contrast, stronger staining for COL type $\times$ (left panels) and ALP (right panels) was found in all chondrogenic groups of aggregates tested (Figure $5 \mathrm{~b}$ to $5 \mathrm{e}$ ). Notably, the strongest staining of the matrix for Col type $\mathrm{X}$ was seen in the IHH only group (Figure $5 \mathrm{~b}$, left panels), while the most extensive staining for ALP was seen the $\mathrm{IHH}+$ BMP-2 group and the BMP-2-only positive controls after 21 days of culture (Figure $5 \mathrm{~d}$, e, right panels).

For evaluation of cell viability and apoptosis (Figure 6) following adenoviral gene transfer using $\mathrm{IHH}$ gene transfer alone (Figure 6b) or in combination with TGF$\beta 1$ (Figure 6c) or BMP-2 (Figure 6d) compared with untransduced controls (Figure 6a), aggregate cultures were examined using double fluorescence staining with Annexin 5-Cy3/6-carboxyfluorescein diacetate. All groups revealed equivalent high levels of green fluorescence (viable cells) after 10 and 21 days of culture (left panels). In the apoptosis detection assay (Figure 6, right panels), only very few cells were Annexin 5-positive (red

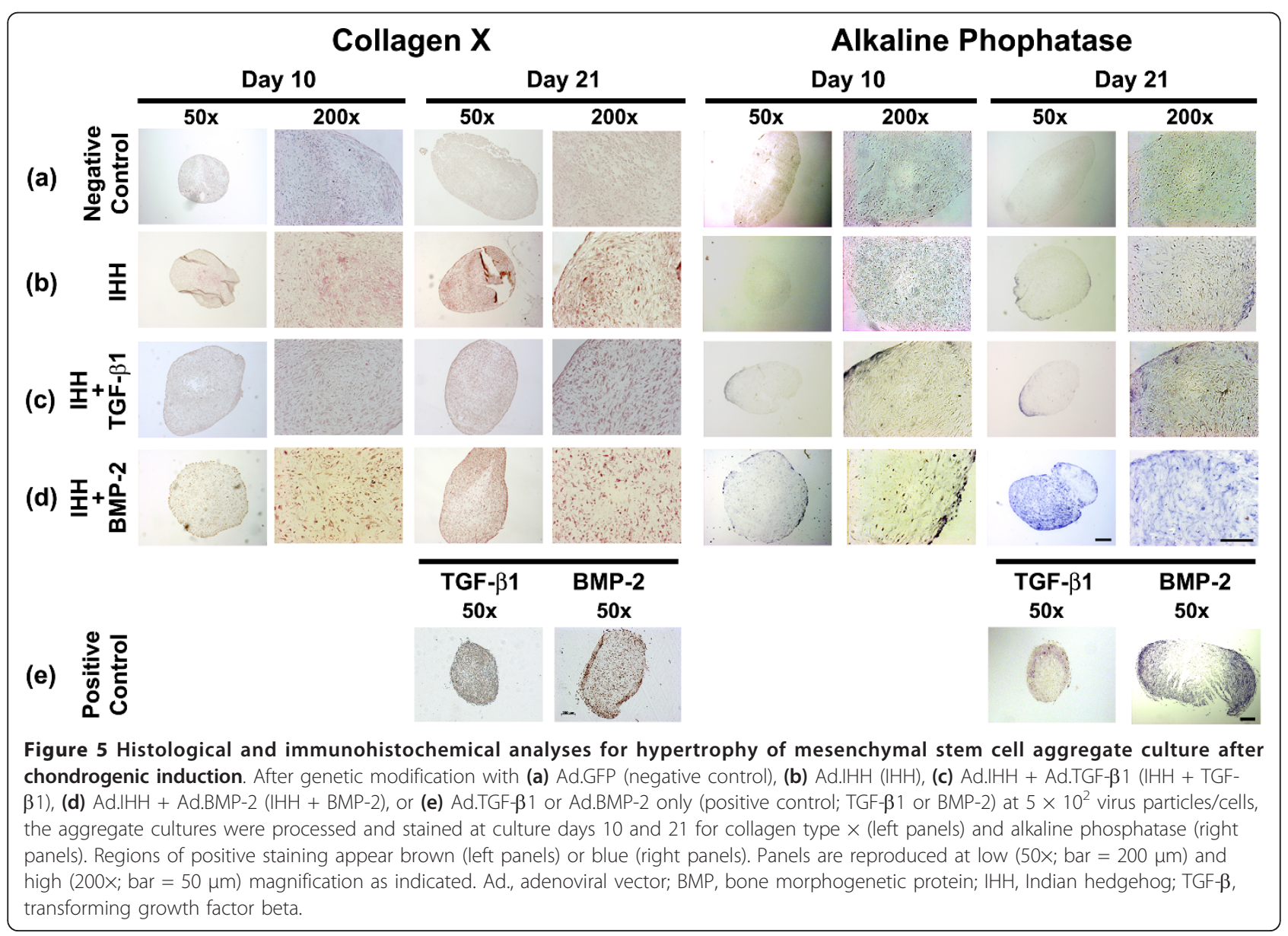




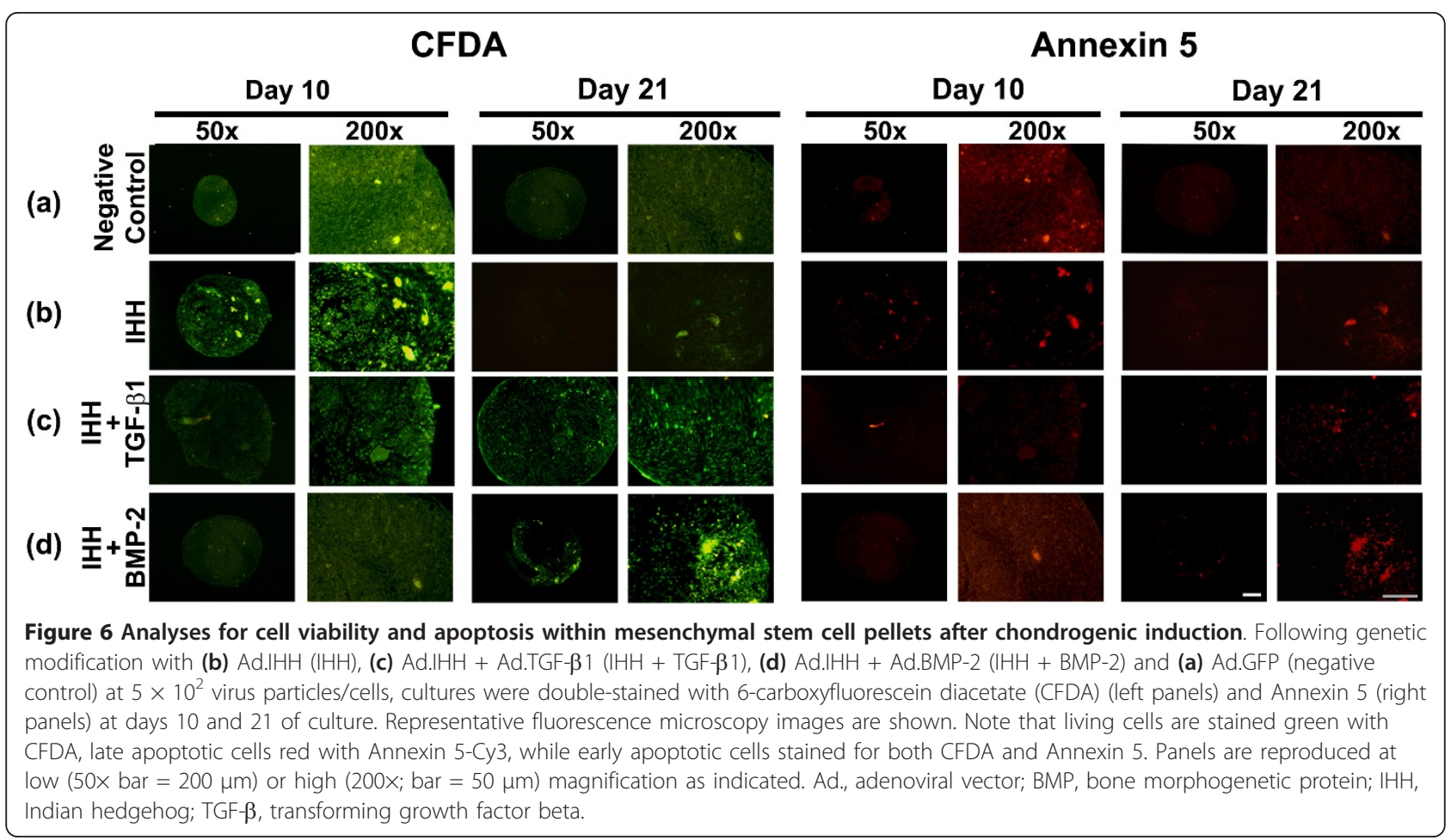

fluorescent) in the control group (Figure 6a), as well as in the IHH group (Figure $6 \mathrm{~b}$ ) or the $\mathrm{IHH}+\mathrm{TGF}-\beta 1$ group (Figure 6c), while many Annexin 5-positive cells were found in the $\mathrm{IHH}+\mathrm{BMP}-2$ group (Figure 6d).

\section{Biochemical analyses of cell proliferation, GAG content and ALP activity}

As primary MSCs were shown to be amenable to adenoviral gene transfer, and to undergo chondrogenesis upon stimulation with $\mathrm{IHH}$ alone or in combination with TGF- $\beta 1$ or BMP-2, we examined the effects of these treatments on cell proliferation using the ATP assay compared with marker gene transduced controls (Figure 7a). Initially, at days 3 and 7, cell proliferation rates in MSC aggregates were high, and they declined over time thereafter, without significant differences between all groups tested (Figure 7a).

Quantitative assessment of GAG synthesis revealed significantly enhanced GAG levels of all treatment groups that received $\mathrm{IHH}$ relative to controls (Figure 7b), while major differences in the pattern of GAG synthesis over time among the chondrogenic groups $\mathrm{IHH}, \mathrm{IHH}+\mathrm{TGF}-\beta 1$, or $\mathrm{IHH}+\mathrm{BMP}-2$ could not be resolved (Figure $7 \mathrm{~b}$ ).

Chondrogenic hypertrophy was quantified using ALP activity (Figure 7c), which was found significantly elevated at days 7,14 and 21 of culture in the $\mathrm{IHH}+$ BMP-2 modified aggregates compared with all other groups, whereas significantly higher values in the $\mathrm{IHH}+$
TGF- $\beta 1$ transduced cultures compared with the GFP controls could only be resolved at day 21 (Figure 7c).

\section{Evaluation of chondrogenic marker gene expression over} time

To explore the effects of $\mathrm{IHH}$ gene delivery alone or in combination with TGF- $\beta 1$ or BMP- 2 on chondrogenesis and hypertrophy compared with controls, we examined the time course for expression of genes associated with chondrogenesis and hypertrophic maturation using semi-quantitative RT-PCR (Figure 8).

Expressions of mRNAs from the chondrogenic marker genes COL type II, AGN, COMP, fibromodulin and SOX9 were upregulated in the IHH, $\mathrm{IHH}+\mathrm{TGF}-\beta 1$, and $\mathrm{IHH}+$ BMP-2 groups compared with controls (Ad.GFP), which were not chondrogenic and expressed only very low levels of the chondrogenic genes COL type II, AGN, fibromodulin and SOX9 (Figure 8a). Although expressed at lower levels compared with the chondrogenic groups $\mathrm{IHH}, \mathrm{IHH}+\mathrm{TGF}-\beta 1$, and $\mathrm{IHH}+\mathrm{BMP}-2$, above-baseline levels of expressions were found for COMP in the Ad. GFP controls (Figure 8a). Clear-cut differences in the expression pattern of the chondrogenic markers between the chondrogenic groups $\mathrm{IHH}, \mathrm{IHH}+\mathrm{TGF}-\beta 1$, or $\mathrm{IHH}+$ BMP-2 could not be resolved (Figure 8a).

Similarly, temporal expression profiles of mRNAs associated with chondrogenic hypertrophy and osteogenesis revealed elevated levels in all groups and time points tested for COL type I, COL type X, ALP, OP, and osteocalcin at 


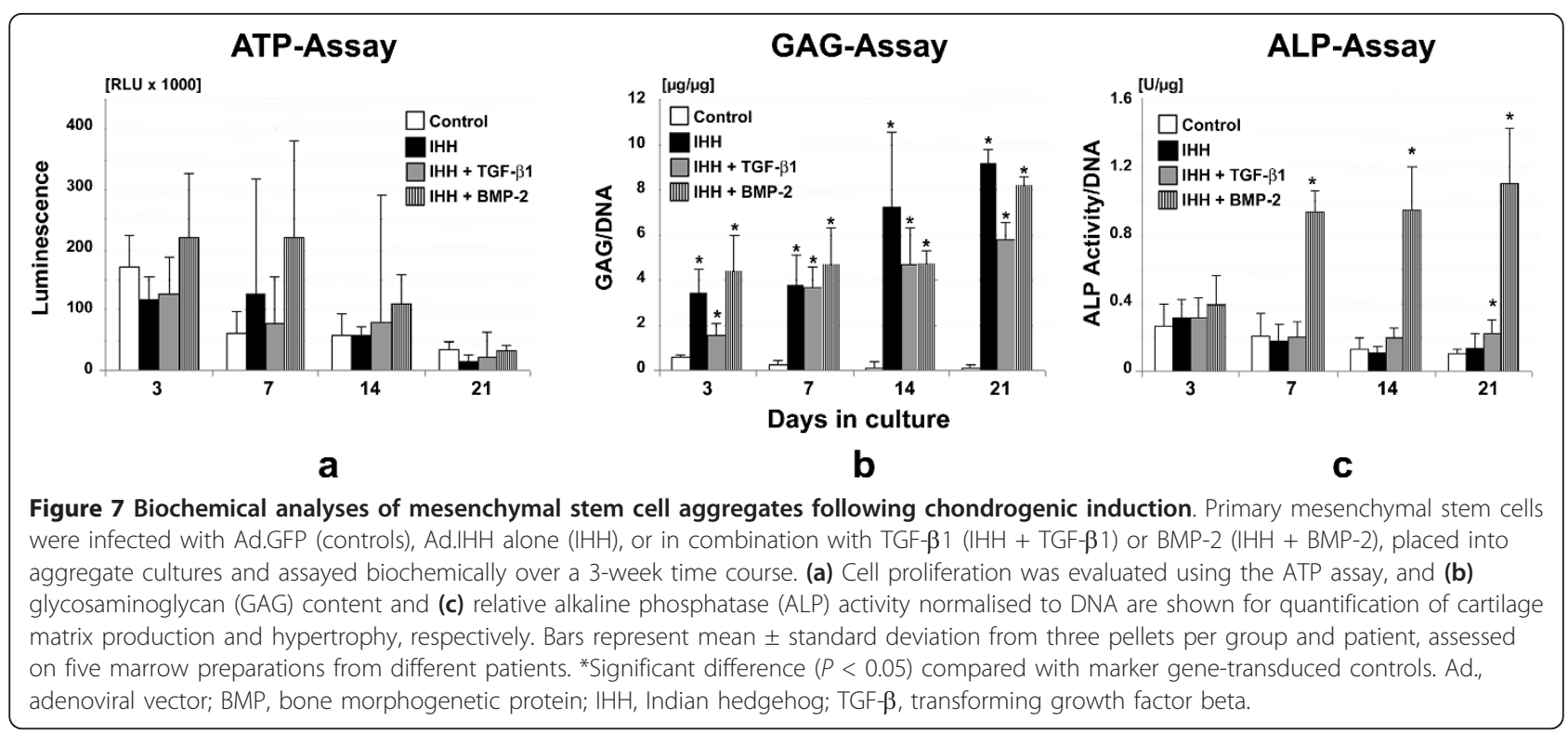

days $3,7,14$ and 21 of culture (Figure $8 \mathrm{~b}$ ). While the chondrogenic groups IHH, IHH + TGF- $\beta 1$, and IHH + BMP-2 showed markedly increased mRNA levels for COL type $\mathrm{X}$ and ALP compared with the marker gene controls, expressions for COL type I, OP and osteocalcin appeared not to be strongly regulated by the different groups (Figure $8 b$ ). Again, major differences between the different chondrogenic groups IHH, IHH + TGF- $\beta 1$, or IHH + BMP-2 could not be detected.

\section{Discussion}

IHH belongs to the hedgehog protein family, which also includes sonic hedgehog (SHH) and desert hedgehog
[21]. Following binding to their cell surface receptors patched-1 and smoothened, hedgehog proteins signal via members of the Gli family of transcription factors (Gli1, Gli2 and Gli3) at the end of the pathway, which are essential regulators of cell fate and patterning in the developing skeleton [22]. In this work, we used the pellet culture system to analyse whether adenoviral delivery of IHH can lead to chondrogenesis of primary MSCs in vitro, and to evaluate the extent of hypertrophy alone and together with TGF- $\beta 1$ or BMP-2.

Delivery of IHH via adenoviral vectors alone or in combination led to reproducible chondrogenesis in human MSC pellet cultures, as shown qualitatively by staining (a)

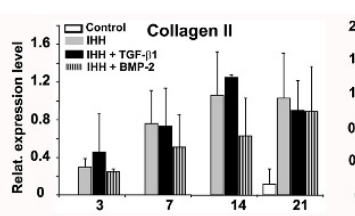

(b)

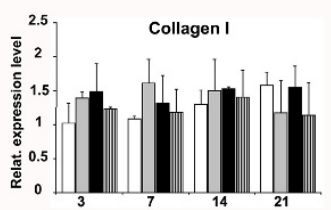

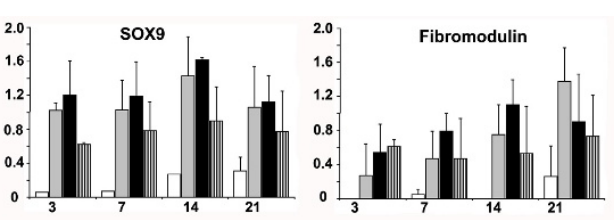

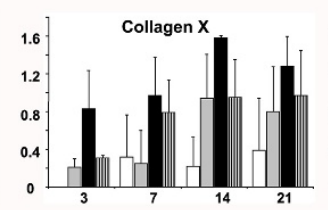

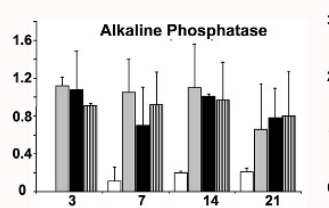

Days in culture
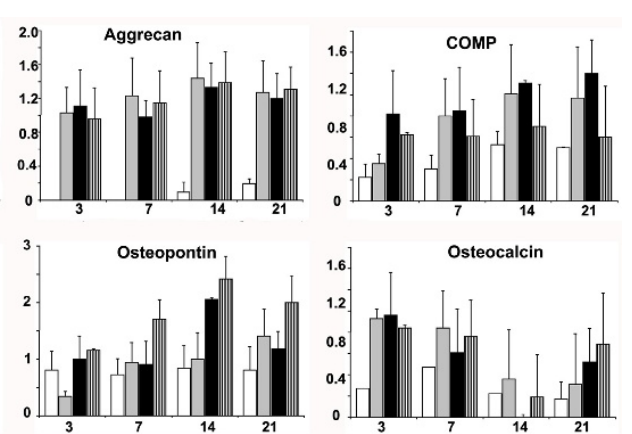

Figure 8 Time course of gene expression assessed by semiquantitative RT-PCR of mesenchymal stem cell pellet cultures. Pellets transduced with Ad.GFP (control), Ad.IHH alone (IHH), or Ad.IHH in combination with Ad.TGF- $\beta 1$ (IHH + TGF- $\beta 1)$ or BMP-2 (IHH + BMP-2) were analysed over time. (a) Expressions for the chondrogenic mRNAs collagen (COL) type II, aggrecan core protein, cartilage oligomeric matrix protein (COMP), fibromodulin, or sex determining region Y-box 9 (SOX9) at days 3, 7, 14, or 21 of culture are shown, respectively. (b) Expressions of mRNAs associated with chondrogenic hypertrophy and osteogenesis of COL type I, COL type X, alkaline phosphatase, osteopontin, or osteocalcin at days 3, 7, 14, or 21 of culture are shown, respectively. Expressions of elongation factor-1 $\alpha$ served as the housekeeping gene and internal control. Primer details are shown in Table 1. Ad., adenoviral vector; BMP, bone morphogenetic protein; IHH, Indian hedgehog; TGF- $\beta$, transforming growth factor beta. 
with Alcian Blue, COL type II and CS4 (Figures 3 and 4) and quantitatively using the GAG assay (Figure 7b). This corresponds to findings in the same model, when adenoviral delivery of TGF- $\beta 1[8,15]$, BMP-4 [11] or BMP-2 $[8,11,15]$ was used. However, combined delivery of IHH together with TGF- $\beta 1$ or BMP- 2 was not able to elicit synergistic effects with respect to the extent of chondrogenesis compared with single IHH delivery (Figures 3, 4 and $7 \mathrm{~b}$ ). This is in agreement with findings of combined gene delivery of TGF- $\beta 1$ and BMP- 2 in the same setup, where additive effects were also absent [23]. In contrast, synergistic effects on transgene expression and chondrogenesis were reported, when TGF- $\beta 1$ or BMP- 2 were administered together with insulin-like growth factor-1 (IGF-1) [23], indicating that the choice of transgenes plays pivotal roles to induce additive chondrogenic effects. Furthermore, increased dosing of adenoviral vectors was shown to be detrimental for chondrogenesis in this model [23], which was the main reason for not increasing the adenoviral dosage in this study. Notably, pellet cultures of all groups decreased levels of cell proliferation over time, with the highest levels being seen in the IHH + BMP-2 groups (Figure 7a). This also corresponds to previous findings, where high levels of cell proliferation and metabolic activity were seen in BMP-4modified and BMP-2-modified aggregates throughout the 3 weeks of culture [11]. Furthermore, signs of chondrogenic hypertrophy were noticed in MSC pellet cultures transduced with $\mathrm{IHH}$ alone and together with TGF- $\beta 1$, but were most abundant in the IHH + BMP-2 group, as assessed by expression for ALP, COL type $X$ and Annexin 5 (Figures 5 and 6). This also concurs with previous results, where BMP-2-infected pellets revealed higher levels of hypertrophy compared with TGF- $\beta 1$ [23] or BMP-4 [11].

The data on expression of marker genes for chondrogenesis and hypertrophy (Figure 8) are in general agreement with the biochemical (Figure 7) and histological observations (Figures 3 to 6), showing strong presence of chondrogenic transcripts in aggregates after IHH stimulation, such as COL type II, AGN, COMP and SOX9. Levels of mRNAs encoding the hypertrophy-associated genes COL type $\mathrm{X}$ and OP were also present in all $\mathrm{IHH}-$ modified groups, compared with controls (Figure 8), and are in general agreement with previous observations where gene delivery of BMP-2 revealed high levels of hypertrophy $[11,23]$.

Our results are in agreement with those of Kellner and colleagues, who used recombinant hedgehog proteins for generation of chondrocyte-based cartilage constructs in vitro [24]. In their study, recombinant IHH was as effective as the protein family member $\mathrm{SHH}$ to increase levels of GAG synthesis, when proteins were used in dipalmitoylated form at $1,000 \mathrm{ng} / \mathrm{ml}$ [24]. In our study, however, IHH was detected at much lower concentration (Figure 2a) but was also very efficient in stimulating chondrocyte matrix synthesis by MSC aggregates (Figures 3, 4 and 7b), which is probably due to the efficient pericellular distribution of the IHH transgene product following adenoviral transduction.

Our data also correspond to positive effects of hedgehog proteins seen in chondrogenic murine ATDC5 or RMD-1 cells in vitro, where administration of transgenic $\mathrm{IHH}$ and SHH led to increased chondrogenic matrix formation [25]. In contrast to our study, however, Enomoto-Iwamoto and colleagues report on additive effects by treatment of IHH or SHH together with BMP-2 protein, which we attribute to the differences in protein delivery and target cell that were used in both experimental settings. This study also showed that $\mathrm{IHH}$ and SHH administration upregulated the expression of Ptc-1 and Gli-1 in RMD-1 and ATDC-5 cells, while Smo, BMP-2 and BMP-4 were unregulated but present and BMP-5 and BMP-7 were undetectable in these cell types [25], indicative of the major regulatory chondrogenic pathways that are also likely to be involved in our study using adult human MSCs.

Furthermore, experiments in SHH knockout mice with defective tracheal cartilage formation revealed that SOX9 was a downstream regulator of $\mathrm{SHH}$, and that cartilage formation by exogenous administration with either $\mathrm{SHH}$ or BMP-4 could be rescued, indicating important roles for both factors on chondrogenesis [26]. This corresponds to in vitro data from ATDC-5 cells, where exogenously administered $\mathrm{IHH}$ upregulated the gene expression of COL type $\mathrm{X}$ and osteoprotegerin ligand, while it did not modulate the expression of $\mathrm{IHH}$ itself, BMP-4, BMP-6, TGF- $\beta 1$, or TGF- $\beta 2$ [27].

Nonetheless, there are also in vivo data on the formation of ectopic cartilage and bone in nude mice after intramuscular SHH and $\mathrm{IHH}$ administration [25], indicating the regenerative potential of such methodology. Moreover, Grande and colleagues were able to show improved cartilage regeneration in vivo, when genetically modified periosteal cells to express SHH or BMP-7 were administered orthotopically to osteochondral defects in a rabbit model [28]. Although no differences between both factors were delineated in this study, the issue of hypertrophy in the context of hedgehog factors was not further examined [28].

Much of the current knowledge about IHH is derived from research in the developing skeleton, where chondrocytes are condensed into cartilage elements during the process of endochondral ossification, and progress through stages of proliferation and hypertrophic differentiation, before they ultimately terminally differentiate, undergo apoptosis and are replaced by bone [29]. IHH has been shown to be involved as key regulator during several 
of these processes [14]. First, IHH is required for synthesis of PTHrP and interacts with PTHrP in a negative feedback loop regulating the pace of hypertrophic differentiation [30,31]. Apart from the action of IHH via PTHrP, further studies also indicate direct independent effects of IHH on chondrocyte proliferation and the ossification process, thus coordinating several different steps of endochondral bone formation [29,32]. Furthermore, the transcription factor Alf4 was shown to be required in chondrocytes for IHH expression, which subsequently, via the paracrine effects of $\mathrm{IHH}$, dominates the role of Alf4 in osteoblasts during development for the control of early osteogenesis and skeletal growth [33]. Postnatally, the growth plate undergoes major structural and functional changes, with PTHrP being expressed in resting zone cartilage - a site that differs from the embryonic source, the periarticular cells - supporting the hypothesis that the embryonic IHHPTHrP feedback loop is maintained in the postnatal growth plate [34]. These observations from the developing skeleton grossly correspond to our findings using adult MSCs, as IHH was shown be able to effectively induce and regulate several steps during chondrogenesis, including proliferation, differentiation, hypertrophy and apoptosis (Figures 2 to 7). Forced overexpression of IHH, however, might have resulted in an imbalance within the finely tuned regulative system with PTHrP that may have influenced the missing modulation of hypertrophy in our system. This is in contrast to the findings of Minina and colleagues in the cartilage elements of transgenic mice, where IHH overexpression resulted in a delayed onset of hypertrophic differentiation [35].

Notably, IHH only revealed the strongest staining of the matrix with COL type $\mathrm{X}$ and only very low levels of ALP activity, while most extensive staining for ALP was seen in the IHH + BMP-2 group and the BMP-2-only positive controls with only pericellular COL type $\mathrm{X}$ staining (Figure 5). This indicates that COL type X and ALP, both markers for chondrogenic hypertrophy, might be differentially regulated by IHH or BMP-2. This corresponds to findings of our own group and others in MSCs using TGF- $\beta 1$ or BMP-2 [15,23], TGF- $\beta 1$ or thyroid hormone [36], or BMP-4 or BMP-2 [11,37], where a similar differential regulation of these markers could also be observed. This is also in agreement with findings in the literature on different cell types, where COL type X precedes ALP expression in growth plate chondrocytes [38,39], costal cartilage [40] or MSCs [12].

This corresponds to elevated levels of COL type II and reduced levels of COL type $\mathrm{X}$ expression by TGF- $\beta 1$-stimulated MSC aggregates upon stimulation with PTH hormone [41] or PTHrP in vitro [12,42]. Reduced levels of hypertrophy were also confirmed, when recombinant PTHrP was employed in an ectopic model of chondrogenesis in vivo using adult MSCs $[12,42,43]$. In our system, however, using adenoviral IHH gene delivery in vitro, no inhibitory effects on chondrogenic hypertrophy were evident. This pattern might change when $\mathrm{IHH}$ genes are delivered to cartilage defects in vivo - the clarifying experiments are underway.

Interestingly, during endochondral ossification, several other groups of signalling systems have been found to interact with IHH [29]. For example, several BMPs, such as BMP-2, are thought to act downstream of $\mathrm{IHH}$, serving as secondary signals mediating the IHH signals to the periarticular perichondrium to induce PTHrP [29]. BMPs might also reciprocally act back on the prehypertrophic chondrocytes, thereby coordinating hypertrophic differentiation with the differentiation of the periosteum [29]. This is in agreement with reports of BMP-2 action on chondrogenesis and hypertrophy, which are in part regulated via HIF1 $\alpha$ activation and vasculature formation [44]. This corresponds to our data, as highest levels of hypertrophy and apoptosis were seen in the group that co-expressed IHH and BMP-2 or BMP-2 alone, compared with the IHH + TGF- $\beta 1$ or IHH only groups (Figures 5 to 8 ). This corresponds to the findings in several transgenic mouse models showing that, in particular, BMP- 2 and TGF- $\beta 1$ can have agonistic and antagonistic effects on proliferation and chondrogenesis and IHH regulation [45].

Moreover, IGF-1 seems also to be importantly involved in IHH/PTHrP signalling - as cartilage-specific IGF-1 receptor knockout mice revealed growth retardation with reduced chondrocyte proliferation and decreased $\mathrm{IHH}$ expression, while PTHrP was upregulated [33]. This involvement could also be confirmed in vitro using in IGF-1 receptor knockout in adult cells, indicating that the IGF-1 receptor in chondrocytes controls cell growth, survival, and differentiation in embryonic and postnatal growth in part by regulating the IHH/PTHrP pathway [33].

Finally, there are many more regulators of chondrocyte hypertrophy and terminal differentiation such as vitamin D3 [46,47] or fibroblast growth factor receptor-3 [29], which are also interacting with the IHH/PTHrP pathway and it becomes more obvious that the single steps of endochondral ossification are tightly coordinated, which in the same way basically holds true for in vitro chondrogenesis and hypertrophy of adult MSCs. Although significant progress has been made during the last years in analysing the signals regulating endochondral ossification in the developing embryo, complete understanding of the control system in adult cells and tissues will require further extensive studies.

\section{Conclusion}

$\mathrm{IHH}$ gene transfer via adenoviral vectors alone and in combination with TGF- $\beta 1$ or BMP- 2 efficiently induces chondrogenesis in aggregate cultures of human primary 
MSCs. The appearance of chondrocyte hypertrophy in this system following 3 weeks of in vitro culture could not be obviated by $\mathrm{IHH}$, however, and was strongly present when BMP-2 was co-expressed. Whether IHH can induce chondrogenesis while modulating hypertrophy in vivo therefore remains to be seen. This gene transfer technology might thus be used to improve the outcome of MSC-based approaches to cartilage regeneration in humans in the future.

\section{Abbreviations}

AGN: aggrecan core protein; ALP: alkaline phosphatase; Ad:: adenoviral vector; BMP: bone morphogenetic protein; COL: collagen; CS4: chondroitin4-sulphate; COMP: cartilage oligomeric matrix protein; DMEM: Dulbecco's modified Eagle's medium; EF-1a: elongation factor-1a; ELISA: enzyme-linked immunosorbent assay; GAG: glycosaminoglycan; GFP: green fluorescent protein; H \& E: haematoxylin and eosin; IGF-1: insulin-like growth factor-1; $\mathrm{HH}$ : Indian hedgehog; MSC: mesenchymal stem cell; OP: osteopontin; PCR: polymerase chain reaction; PTHrP: parathyroid hormone-related peptide; RT: reverse transcription; SHH: sonic hedgehog; SOX9: sex determining region Ybox 9; TGF- $\beta$ : transforming growth factor beta.

\section{Acknowledgements}

The authors are grateful to Viola Monz and Martina Regensburger for expert technical assistance, and to Patrick Prager for his help with the manuscript revisions. This work was supported in parts by grants STE 1051/2-1 and 3/1 from the Deutsche Forschungsgemeinschaft (DFG) to AFS and UN, and by grants D-101 and 219 to AFS from the Interdisciplinary Center for Clinical Research (IZKF) Würzburg. This publication was funded by the German Research Foundation (DFG) and the University of Wuerzburg in the funding programme Open Access Publishing.

\section{Author details}

'Department of Orthopaedic Surgery, König-Ludwig-Haus, Center for Musculoskeletal Research, Julius-Maximilians-University, Brettreichstraße 11, Würzburg 97074, Germany. ${ }^{2}$ Department of Orthopaedics and Rehabilitation, University of Florida, 1600 SW Archer Road, Gainesville, FL 32610, USA.

\section{Authors' contributions}

All authors read and approved the manuscript and contributed to the study design, data analysis, interpretation of data, and drafting and revision of the manuscript. The data were generated by AFS, MK, SG and SCG, and a data review committee (AFS, SCG, SG, FG, FJ, UN and MR) analysed the data.

\section{Competing interests}

The authors declare that they have no competing interests.

Received: 20 February 2012 Revised: 3 July 2012

Accepted: 20 July 2012 Published: 20 July 2012

\section{References}

1. Steinert AF, Ghivizzani SC, Rethwilm A, Tuan RS, Evans CH, Noth U: Major biological obstacles for persistent cell-based regeneration of articular cartilage. Arthritis Res Ther 2007, 9:213.

2. Wakitani S, Mitsuoka T, Nakamura N, Toritsuka Y, Nakamura Y, Horibe S. Autologous bone marrow stromal cell transplantation for repair of fullthickness articular cartilage defects in human patellae: two case reports. Cell Transplant 2004, 13:595-600.

3. Kuroda R, Ishida K, Matsumoto T, Akisue T, Fujioka H, Mizuno K, Ohgushi H, Wakitani S, Kurosaka M: Treatment of a full-thickness articular cartilage defect in the femoral condyle of an athlete with autologous bonemarrow stromal cells. Osteoarthritis Cartilage 2007, 15:226-231.

4. Noth U, Steinert AF, Tuan RS: Technology insight: adult mesenchymal stem cells for osteoarthritis therapy. Nat Clin Pract Rheumatol 2008, 4:371-380

5. Fortier LA, Barker JU, Strauss EJ, McCarrel TM, Cole BJ: The role of growth factors in cartilage repair. Clin Orthop Relat Res 2011, 469:2706-2715.
6. Nesic D, Whiteside R, Brittberg M, Wendt D, Martin I, Mainil-Varlet P: Cartilage tissue engineering for degenerative joint disease. Adv Drug Deliv Rev 2006, 58:300-322.

7. Evans $\mathrm{CH}$, Robbins PD, Ghivizzani SC, Wasko MC, Tomaino MM, Kang R, Muzzonigro TA, Vogt M, Elder EM, Whiteside TL, Watkins SC, Herndon JH: Gene transfer to human joints: progress toward a gene therapy of arthritis. Proc Natl Acad Sci USA 2005, 102:8698-8703.

8. Steinert AF, Noth $U$, Tuan RS: Concepts in gene therapy for cartilage repair. Injury 2008, 39:S97-S113.

9. Cucchiarini M, Madry H: Gene therapy for cartilage defects. J Gene Med 2005, 7:1495-1509

10. Gelse K, Schneider H: Ex vivo gene therapy approaches to cartilage repair. Adv Drug Deliv Rev 2006, 58:259-284.

11. Steinert AF, Proffen B, Kunz M, Hendrich C, Ghivizzani SC, Noth U, Rethwilm A, Eulert J, Evans $\mathrm{CH}$ : Hypertrophy is induced during the in vitro chondrogenic differentiation of human mesenchymal stem cells by bone morphogenetic protein- 2 and bone morphogenetic protein-4 gene transfer. Arthritis Res Ther 2009, 11:R148.

12. Pelttari K, Winter A, Steck E, Goetzke K, Hennig T, Ochs BG, Aigner T, Richter W: Premature induction of hypertrophy during in vitro chondrogenesis of human mesenchymal stem cells correlates with calcification and vascular invasion after ectopic transplantation in SCID mice. Arthritis Rheum 2006, 54:3254-3266.

13. Gelse K, von der Mark K, Aigner T, Park J, Schneider H: Articular cartilage repair by gene therapy using growth factor-producing mesenchymal cells. Arthritis Rheum 2003, 48:430-441.

14. Vortkamp A, Lee K, Lanske B, Segre GV, Kronenberg HM, Tabin CJ: Regulation of rate of cartilage differentiation by Indian hedgehog and PTH-related protein. Science 1996, 273:613-622.

15. Palmer GD, Steinert A, Pascher A, Gouze E, Gouze JN, Betz O, Johnstone B, Evans $\mathrm{CH}$, Ghivizzani SC: Gene-induced chondrogenesis of primary mesenchymal stem cells in vitro. Mol Ther 2005, 12:219-228.

16. Hardy S, Kitamura M, Harris-Stansil T, Dai Y, Phipps ML: Construction of adenovirus vectors through Cre-lox recombination. J Virol 1997, 71:1842-1849.

17. Sambrook J, Russell DW: In Molecular Cloning: A Laboratory Manual. Volume 1.. 3 edition. New York: CSHL Press; 2001.

18. Palmer G, Gouze E, Gouze JN, Betz O, Evans CH, Ghivizzani SC: Gene transfer to articular chondrocytes with recombinant adenovirus. Methods Mol Biol 2003, 215:235-246.

19. Noth U, Tuli R, Osyczka AM, Danielson KG, Tuan RS: In vitro engineered cartilage constructs produced by press-coating biodegradable polymer with human mesenchymal stem cells. Tissue Eng 2002, 8:131-144.

20. Steinert AF, Kunz M, Prager P, Barthel T, Jakob F, Noth U, Murray MM, Evans $\mathrm{CH}$, Porter RM: Mesenchymal stem cell characteristics of human anterior cruciate ligament outgrowth cells. Tissue Eng Part A 2011, 17:1375-1388.

21. McMahon LA, Prendergast PJ, Campbell VA: A comparison of the involvement of $\mathrm{p} 38, \mathrm{ERK} 1 / 2$ and $\mathrm{PI} 3 \mathrm{~K}$ in growth factor-induced chondrogenic differentiation of mesenchymal stem cells. Biochem Biophys Res Commun 2008, 368:990-995.

22. Rockel JS, Alman BA: Don't hedge your bets: hedgehog signaling as a central mediator of endochondral bone development and cartilage diseases. J Orthop Res 2011, 29:810-815.

23. Steinert AF, Palmer GD, Pilapil C, Noth U, Evans CH, Ghivizzani SC: Enhanced in vitro chondrogenesis of primary mesenchymal stem cells by combined gene transfer. Tissue Eng Part A 2009, 15:1127-1139.

24. Kellner K, Lang K, Papadimitriou A, Leser U, Milz S, Schulz MB, Blunk T, Gopferich A: Effects of hedgehog proteins on tissue engineering of cartilage in vitro. Tissue Eng 2002, 8:561-572.

25. Enomoto-Iwamoto $M$, Nakamura $T$, Aikawa $T$, Higuchi $Y$, Yuasa $T$, Yamaguchi A, Nohno T, Noji S, Matsuya T, Kurisu K, Koyama E, Pacifici M, Iwamoto M: Hedgehog proteins stimulate chondrogenic cell differentiation and cartilage formation. J Bone Miner Res 2000, 15:1659-1668.

26. Park J, Zhang JJ, Moro A, Kushida M, Wegner M, Kim PC: Regulation of Sox 9 by Sonic Hedgehog (Shh) is essential for patterning and formation of tracheal cartilage. Dev Dyn 2010, 239:514-526.

27. Akiyama $\mathrm{H}$, Shigeno $\mathrm{C}$, lyama $\mathrm{K}$, Ito $\mathrm{H}$, Hiraki $Y$, Konishi J, Nakamura T: Indian hedgehog in the late-phase differentiation in mouse chondrogenic EC cells, ATDC5: upregulation of type $X$ collagen and 
osteoprotegerin ligand mRNAs. Biochem Biophys Res Commun 1999, 257:814-820.

28. Grande DA, Mason J, Light E, Dines D: Stem cells as platforms for delivery of genes to enhance cartilage repair. J Bone Joint Surg Am 2003, 85A:111-116.

29. Vortkamp A: Interaction of growth factors regulating chondrocyte differentiation in the developing embryo. Osteoarthritis Cartilage 2001, 9 S109-S117.

30. Lanske B, Karaplis AC, Lee K, Luz A, Vortkamp A, Pirro A, Karperien M, Defize LH, Ho C, Mulligan RC, Abou-Samra AB, Jüppner H, Segre GV, Kronenberg HM: PTH/PTHrP receptor in early development and Indian hedgehog-regulated bone growth. Science 1996, 273:663-666.

31. Kronenberg HM: PTHrP and skeletal development. Ann N Y Acad Sci 2006, 1068:1-13.

32. Kronenberg HM: Developmental regulation of the growth plate. Nature 2003, 423:332-336

33. Wang W, Lian N, Ma Y, Li L, Gallant RC, Elefteriou F, Yang X: Chondrocytic Atf4 regulates osteoblast differentiation and function via Ihh. Development 2012, 139:601-611.

34. Chau M, Forcinito P, Andrade AC, Hegde A, Ahn S, Lui JC, Baron J, Nilsson O: Organization of the Indian hedgehog - parathyroid hormonerelated protein system in the postnatal growth plate. J Mol Endocrinol 2011, 47:99-107.

35. Minina E, Wenzel HM, Kreschel C, Karp S, Gaffield W, McMahon AP, Vortkamp A: BMP and Ihh/PTHrP signaling interact to coordinate chondrocyte proliferation and differentiation. Development 2001, 128:4523-4534

36. Mueller MB, Tuan RS: Functional characterization of hypertrophy in chondrogenesis of human mesenchymal stem cells. Arthritis Rheum 2008, 58:1377-1388

37. Steinert A, Weber M, Dimmler A, Julius C, Schutze N, Noth U, Cramer H, Eulert J, Zimmermann U, Hendrich C: Chondrogenic differentiation of mesenchymal progenitor cells encapsulated in ultrahigh-viscosity alginate. J Orthop Res 2003, 21:1090-1097.

38. Poole AR, Matsui Y, Hinek A, Lee ER: Cartilage macromolecules and the calcification of cartilage matrix. Anat Rec 1989, 224:167-179.

39. Cheung JO, Hillarby MC, Ayad S, Hoyland JA, Jones CJ, Denton J, Thomas JT, Wallis GA, Grant ME: A novel cell culture model of chondrocyte differentiation during mammalian endochondral ossification. J Bone Miner Res 2001, 16:309-318.

40. Bahrami S, Plate U, Dreier R, DuChesne A, Willital GH, Bruckner P. Endochondral ossification of costal cartilage is arrested after chondrocytes have reached hypertrophic stage of late differentiation. Matrix Biol 2001, 19:707-715.

41. Mwale F, Yao G, Ouellet JA, Petit A, Antoniou J: Effect of parathyroid hormone on type $X$ and type II collagen expression in mesenchymal stem cells from osteoarthritic patients. Tissue Eng Part A 2010, 16:3449-3455.

42. Weiss S, Hennig T, Bock R, Steck E, Richter W: Impact of growth factors and PTHrP on early and late chondrogenic differentiation of human mesenchymal stem cells. J Cell Physiol 2010, 223:84-93.

43. Fischer J, Dickhut A, Rickert M, Richter W: Human articular chondrocytes secrete parathyroid hormone-related protein and inhibit hypertrophy of mesenchymal stem cells in coculture during chondrogenesis. Arthritis Rheum 2010, 62:2696-2706.

44. Gelse K, Muhle C, Knaup K, Swoboda B, Wiesener M, Hennig F, Olk A Schneider $\mathrm{H}$ : Chondrogenic differentiation of growth factor-stimulated precursor cells in cartilage repair tissue is associated with increased HIF1a activity. Osteoarthritis Cartilage 2008, 16:1457-1465.

45. Keller B, Yang T, Chen Y, Munivez E, Bertin T, Zabel B, Lee B: Interaction of TGF $\beta$ and BMP signaling pathways during chondrogenesis. PLOS One 2011, 6:e16421.

46. Klotz B, Mentrup B, Regensburger M, Zeck S, Schneidereit J, Schupp N, Linden C, Merz C, Ebert R, Jakob F: 1,25-dihydroxyvitamin D3 treatment delays cellular aging in human mesenchymal stem cells while maintaining their multipotent capacity. PLoS One 2012, 7:e29959.

47. Dreier R, Gunther BK, Mainz T, Nemere I, Bruckner P: Terminal differentiation of chick embryo chondrocytes requires shedding of a cell surface protein that binds 1,25-dihydroxyvitamin D3. J Biol Chem 2008, 283:1104-1112 doi:10.1186/ar3921

Cite this article as: Steinert et al:: Indian hedgehog gene transfer is a chondrogenic inducer of human mesenchymal stem cells. Arthritis Research \& Therapy 2012 14:R168.

\section{Submit your next manuscript to BioMed Central and take full advantage of:}

- Convenient online submission

- Thorough peer review

- No space constraints or color figure charges

- Immediate publication on acceptance

- Inclusion in PubMed, CAS, Scopus and Google Scholar

- Research which is freely available for redistribution

Submit your manuscript at www.biomedcentral.com/submit
Ciomed Central 